\title{
A Computational Approach to Design Potential Antiviral RNA for 3'UTR Post Transcriptional Gene Silencing of Different Strains of Zika Virus
}

\author{
M.A Hashem*, Moinul Abedin Shuvo and Arifuzzaman \\ Department of Biochemistry and Biotechnology, University of Science and Technology Chittagong (USTC), Foy's Lake, Chittagong-4202, BANGLADESH.
}

\begin{abstract}
Background: Zika virus is a flare-up mosquito-borne virus that manifests itself in sporadic human infections with Zika fever. It has a serious affect in pregnant women. Mother transmits Zika virus infection to her infant during the time of delivery which results in the birth of newborn with microcephaly and some neurological malformations. Molecular studies revealed that the $3^{\prime} U T R$ of Zika virus genome plays a vital role in viral replication and pathogenicity. So, the $3^{\prime}$ UTR can be a suitable target for the prevention of viral multiplications and degree of pathogenicity. The activity of the $3^{\prime}$ UTR of Zika virus genome can be controlled by blocking or down regulating its expression through RNAi technology. RNAi works by silencing or turning off target gene expression using siRNA. Hence there arises an urgent need to design potential siRNA against the target sequence of Zika virus genome to control its replication and pathogenicity. This study is aimed to predict potential siRNA based therapeutics that might be used for the treatment of Zika virus infection. Methods: Designing siRNA against the target region of different strains of Zika virus is difficult due to its genetic diversity. Therefore, the work is done on the basis of rational siRNA designing method by targeting the $3^{\prime}$ UTR of Zika virus strains. The prediction of potential siRNA was done by using various computational tools as searching
\end{abstract}

target sequences, multiple sequences alignment, secondary structure prediction, siRNA-Target sequence interaction prediction and finally the evaluation of effectiveness of predicted and depicted siRNA. Results: Out of sixty siRNA only four potential siRNA were predicted and depicted rationally for silencing $3^{\prime}$ UTR of 37 different Zika virus genome used in the study through RNAi technology. Conclusion: The outcomes of this study are four potential siRNA molecules which might be used as a potential antiviral RNA based therapeutics to suppress the Zika virus mediated infection.

Key words: Antiviral RNA, RNAi technology, siRNA, Zika virus, 3' UTR region.

Correspondence :

M.A Hashem

Department of Biochemistry and Biotechnology. University of Science \& Technology Chittagong. Foy's Lake, Chittagong-4202, BANGLADESH.

Email: hashem_bmb@yahoo.com

DOI: 10.5530/jyp.2017.9.5

\section{INTRODUCTION}

The first Zika virus was isolated from the Rhesus monkey in 1947 and human in 1952. ${ }^{1}$ Thereafter epidemic transmissions of Zika infections were reported in Pakistan, Malaysia, Indonesia in 1977 and 1978, Micronesia in 2007, Cambodia in 2010 and Bangladesh in 2016. ${ }^{2-8}$ Zika virus (family Flaviviridae, genus Flavivirus) is an arthropod-borne arbovirus that is closely related to Spondweni virus, originally transmitted in Africa through a sylvatic cycle involving mainly Aedes vectors (Ae. Africanus, Ae. Luteocephalus, Ae. hensilli, and Ae. Aegypti) and nonhuman primates with humans being occasional hosts. ${ }^{9}$

In recent years, an outbreak of transmission in a dengue-like Aedeshuman-Aedes cycle has been increasingly reported, with nonspecific clinical symptoms (influenza-, dengue-or chikungunya-like syndromes). ${ }^{10,11}$ Furthermore, Zika virus can transmit from infected pregnant women to her infant during delivery which results in microcephaly and some neurological malformations in infant and Guillain-Barré syndrome in adults. ${ }^{12-14}$ Till now, there is no drug against Zika virus or treatment for Zika infection. ${ }^{15}$

Zika virus is a positive-sense single-stranded RNA (10794kb) virus with 2 flanking non-coding regions (5' and 3' non-coding region were typically 0.09-0.1 and 0.3-0.5 kb nucleotide long, respectively). ${ }^{16-18}$ Genome of Zika has open reading frame which encoding polyprotein associated with three structural proteins, Capsid (105 amino acids), premembrane (187 amino acids) and envelope (505 amino acids) and seven nonstructural proteins, NS1 (352 amino acids), NS2A (217 amino acids), NS2B (139 amino acids), NS3 (619 amino acids), NS4A (127 amino acids), NS4B (255 amino acids) and NS5 (905 amino acids). ${ }^{19}$ The 5' UTR (non-coding region) of Zika virus consists of two conserved structural elements such as large stem loop (SLA) and short stem loop (SLB) which are essential for viral RNA synthesis and replication. ${ }^{17,20,21}$ The 3' UTR (non-coding region) contain seven highly conserved secondary stem loop (SL) structure; SL-I, SL-II, SL-III, SL-IV, DB1, DB2 and CRE. ${ }^{18,22}$ The two conserved secondary stem loop SL-II and SL-IV shield the 3'UTR from ribonuclease mediated digestion which is essential for viral induced cytopathicity, pathogenicity and multification. ${ }^{22}$ Moreover, the conserved secondary stem loop, DB1/DB2 and CRE (Cis-acting replication element) take part in viral translation and replication, respectively. ${ }^{18,23}$ Therefore, the 3 ' UTR in different strains of Zika virus, plays a vital role in viral multiplication and pathogenicity. ${ }^{22}$

Growing recognition of the importance of RNA is shedding light on diseases, and on how it might be treated-particularly through a process called RNA interference (RNAi). It has become one of the most exciting frontiers in medicine, in such short order that two of its pioneers, Andrew Fire and Craig Mellow, won the 2006 Nobel Prize for Medicine, just eight years after their key work was published. ${ }^{24}$ RNAi relies on doublestranded RNA molecules called short interfering RNAs (siRNAs), each about 21 units in length. siRNAs interfere with the activity of genes that generate the same sequence in messenger RNA, so that lower quantities of protein are produced. These induce the down regulation of gene

This is an open access article distributed under the terms of the Creative Commons Attribution-NonCommercial-ShareAlike 4.0 License, which allows others to remix, tweak, and build upon the work non-commercially, as long as the author is credited and the new creations are licensed under the identical terms. 
expression in a very sequence-specific manner by the assistance of different enzymes. ${ }^{25}$ It can be introduced into the cell for knockdown of a gene of interest by using various methods. ${ }^{26}$ The technique's medical potential lies in its ability to target particular genes and their protein products with great precision. RNAi can therefore be used to switch off rogue genes, of the sort that drive cancer or other disorders, without messing up the chemistry of healthy cells. As a result, siRNA may also be used for the therapeutic purposes as chemical drugs. ${ }^{27}$ So, RNAi approach is one of the most exciting frontiers in medicines for several clinical cases: CNS disorder, human herpes simplex 1, hypercholesterolemia, hepatitis B virus, hepatitis $\mathrm{C}$ virus. ${ }^{28-32}$

In this computational approach, we have aimed to design a potential siRNA molecule to prevent the expression of 3'UTR of Zika virus on the principle of post-transcriptional gene silencing mechanism.

\section{MATERIALS AND METHODS}

\section{Sequence retrieval}

The nucleotide sequence of 3' UTR of different strains of Zika virus were retrieved from the NCBI database with the following accession numbers $^{33}$ : gi|592746858, gi|592746859, gi|592746860, gi|592746861, gi|592746862, gi|592746863, gi|592746864, gi|592746865, gi|592746866, gi|592746867, gi|592746868, gi|592746869, gi|592746870, gi|592746871, gi|592746872, gi|592746873, gi|592746874, gi|592746875, gi|592746876, gi|592746877, gi|592746878, gi|592746879, gi|592746880, gi|592746881, gi|592746882, gi|592746883, gi|592746884, gi|592746885, gi|592746886, gi|592746887, gi|592746888, gi|592746889, gi|592746890, gi|592746891, gi|592746892, gi|592746893, gi|592746894.

\section{Forecast of siRNA with target position}

Forecast of functional siRNA with target positions of these nucleotides sequences of Zika virus were carried out with the help of the siDirect $2.0^{34}$ with the followed some rules like Ui-Tei, Amarz-guiout, Renold rules and melting temperature $\left(T_{\mathrm{m}}\right)$ should be below $21.5^{\circ} \mathrm{C}$ for potential siRNA duplex. ${ }^{35-37}$

\section{Construction of common target position}

Alignment of the selected siRNA target positions was constructed under default conditions by using Clustal W program. ${ }^{38}$

\section{Analysis of off-target sequence}

Analysis of any off-target sequence resemblance in human genome transcript, blast tool program was used against whole Genebank database by applying expected thresholds value 10 and BLOSUM 62 matrix as the parameter. ${ }^{39}$

\section{Calculation of GC content}

DNA/RNA GC content calculator tool was used to calculate the GC content of the selected siRNA. ${ }^{40}$

\section{Prediction of siRNA secondary structure}

Secondary structure of siRNA was predicted by using the mfold server to calculate the free energy of folding. ${ }^{41}$

\section{Analysis of RNA-RNA interaction}

Analysis of RNA-RNA interaction like thermodynamics of interaction between the target region and predicted siRNA with hybridization energy, RNAcofold Program was used ${ }^{42}$ This software program functions as an extension of McCaskill's partition function algorithm to evaluate probabilities of base pairing, realistic interaction energies and the equilibrium concentration of duplex structures.

Flow chart (Figure 1) showing the complete approaches used for prediction of effective siRNA molecules against 3' UTR region of 37 different strains of Zika virus used in this study.

\section{RESULT AND DISCUSSION}

In this study, we have found total 60 siRNA against 60 target sequences in 3' UTR of 37 Zika virus strains. Among them, 15 target siRNA for 15 Zika strains, 42 target siRNA for 21 Zika strains and 3 target siRNA for 1 Zika strain which fulfilled all the criteria and algorithms of Ui-Tei, Amarzguioui and Reynolds and shown in Supplementary Table. Therefore, maximum 3 siRNA target positions were found for 37 different Zika virus strains. All target sequences were divided into four target groups ( $a, b, c$ and $d$ ) on the basis of their sequence similarity and target position using multiple sequences alignment. This aided the construction of common siRNA against the Zika virus sequences analyzed in this study shown in Figure 2. To reduce off-target effect, $T_{\mathrm{m}}$ should be less than $21.5^{\circ} \mathrm{C} .{ }^{43}$ Based on the nearest neighbor model with the thermodynamic parameters, $T_{\mathrm{m}}$ was calculated for the seed-target duplex. In this tool, predicted siRNA with minimum $T_{\mathrm{m}}$ value at the seed region and result of siDirect defines no possibilities for off targets silencing. In the Table 1 , all the four classified consensus targets were selected on the basis of their off-target similarity that can be suitable for post transcriptional gene silencing of 3' UTR of 37 different strains of Zika virus used in this study. Further, these classified consensus targets were clarified by Blast similarity search of whole the human genome where no off target found. Therefore these four targets have no chances for off target silencing.

So, four clarified consensus siRNA against 3' UTR for 37 strains of Zika Virus were selected for next study. Furthermore, we checked GC\%, free energy for folding and binding of the predicted siRNA with their target sequence.

The GC content of siRNA is an important parameter that represents as the functionality of siRNA. The percentages of predicted siRNA were 42.9\% GC content in consensus A, 38\% GC content in consensus B, 42.9\% GC content in consensus C and $42.9 \%$ GC content in consensus D respectively shown in the Table 1 . siRNA with GC content within the range of $31.6 \%-57.9 \%$, is usually recommended due to its negative correlation between GC-content and RNAi activity. ${ }^{44}$ Four predicted consensus siRNA have found within the range of recommended GC content. The free energy of folding is a significant parameter that illustrates the stability of designed siRNA. To calculate the stability of the consensus siRNA (guide strand), the minimum free energy $(\mathrm{kcal} / \mathrm{mol}$ ) of the optimal folding was computed by using mfold program followed by most used algorithms for the prediction of RNA secondary structure, based on the minimal free energy state for exploring effective folding of siRNA guide strand. In this study the free energy of folding of predicted four siRNA were -3.42 in siRNA A, -1.29 in siRNA B, -1.29 in siRNA C and -1.29 in siRNA $D$ respectively at $37^{\circ} \mathrm{C}$ temperature shown in Table 1 and the secondary structure of these siRNA shown in the Figure 3. Earlier it was recommend that a guide strand siRNA must have smallest free energy for their stability. ${ }^{45}$ Here, predicted siRNA of folding were having minimal free energy. Therefore, this minimal free energy of folding represents the effectiveness of these predicted siRNA and in this study our observations support the findings.

The free energy of binding with target is another parameter for siRNA efficiency. The thermodynamic of RNA-RNA interaction of these consensus siRNA with consensus target sequences was predicted using RNAcofold Program. In this study, the binding of predicted siRNA with their target was -36.00 for consensus target group A, -35.90 for consensus target group B, -37.20 for consensus target group C and -37.10 for consensus target group D shown in the Table 1. This program that recommend the algorithms of RNA folding, calculate and forecast of RNARNA interactions, related to our work on RNA secondary structure. ${ }^{29}$ Therefore, these predicted siRNA represent the smallest hybridization energy for binding with their target sequence. 
M.A Hashem et al.: A Computational Approach to Design Potential Antiviral RNA

Table 1: Four designed siRNA molecules with GC\%, free energy of folding and free energy of binding with target.

\begin{tabular}{|c|c|c|c|c|c|c|}
\hline 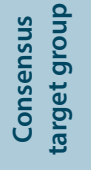 & 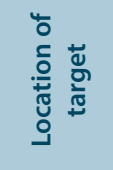 & siRNA target within consensus target & Designed siRNA duplex at $37^{\circ} \mathrm{C}$ & GC\% & 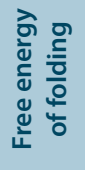 & 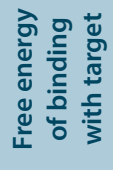 \\
\hline a & $271-293$ & GTGCTGTAAGCACCAATTTCAAT & $\begin{array}{l}\text { UGAAAUUGGUGCUUACAGCAC * } \\
\text { GCUGUAAGCACCAAUUUCAAU }\end{array}$ & $42.9 \%$ & -3.42 & -36.00 \\
\hline $\mathrm{b}$ & $186-208$ & TAGGATCATAGGTGATGAAGAAA & $\begin{array}{l}\text { UCUUCAUCACCUAUGAUCCUA ** } \\
\text { GGAUCAUAGGUGAUGAAGAAA }\end{array}$ & $38 \%$ & -1.29 & -35.90 \\
\hline c & $186-208$ & CAGGATCATAGGTGATGAAGAAA & $\begin{array}{l}\text { UCUUCAUCACCUAUGAUCCUG *** } \\
\text { GGAUCAUAGGUGAUGAAGAAA }\end{array}$ & $42.9 \%$ & -1.29 & -37.20 \\
\hline $\mathrm{d}$ & $186-208$ & ACGGATCATAGGTGATGAAGAGA & $\begin{array}{l}\text { UCUUCAUCACCUAUGAUCCGU **** } \\
\text { GGAUCAUAGGUGAUGAAGAGA }\end{array}$ & $42.9 \%$ & -1.29 & -37.10 \\
\hline
\end{tabular}

Here, 4 predicted siRNA: ${ }^{*}$ Consensus siRNA A, ${ }^{* \star}$ Consensus siRNA B, ${ }^{* * *}$ Consensus siRNA C and ${ }^{* * *}$ Consensus siRNA D respectively for 37 different strains of Zika virus used in this study.

Supplementary Table: Predicted siRNA target sequences with siRNA for 3' UTR of 37 different strains of Zika virus.

\begin{tabular}{|c|c|c|c|c|c|}
\hline $\mathrm{S} / \mathrm{N}$ & $\begin{array}{c}\text { accession } \\
\text { number }\end{array}$ & Target & $\begin{array}{l}\text { Location of target } \\
\text { position }\end{array}$ & siRNA target sequence & Designed siRNA \\
\hline \multirow{2}{*}{1} & \multirow{2}{*}{ gi|592746858 } & Target 1 & $186-208^{\text {ii }}$ & TAGGATCATAGGTGATGAAGAAA & $\begin{array}{l}\text { UCUUCAUCACCUAUGAUCCUA } \\
\text { GGAUCAUAGGUGAUGAAGAAA }\end{array}$ \\
\hline & & Target 2 & $271-293^{\text {ii }}$ & GTGCTGTAAGCACCAATTTCAAT & $\begin{array}{l}\text { UGAAAUUGGUGCUUACAGCAC } \\
\text { GCUGUAAGCACCAAUUUCAAU }\end{array}$ \\
\hline \multirow{2}{*}{2} & \multirow{2}{*}{ gi|592746859 } & Target 1 & $186-208^{\text {ii }}$ & TAGGATCATAGGTGATGAAGAAA & $\begin{array}{l}\text { UCUUCAUCACCUAUGAUCCUA } \\
\text { GGAUCAUAGGUGAUGAAGAAA }\end{array}$ \\
\hline & & Target 2 & $271-293^{\text {ii }}$ & GTGCTGTAAGCACCAATTTCAAT & $\begin{array}{l}\text { UGAAAUUGGUGCUUACAGCAC } \\
\text { GCUGUAAGCACCAAUUUCAAU }\end{array}$ \\
\hline \multirow{2}{*}{3} & \multirow{2}{*}{ gi|592746860 } & Target 1 & $186-208^{\text {ii }}$ & TAGGATCATAGGTGATGAAGAAA & $\begin{array}{l}\text { UCUUCAUCACCUAUGAUCCUA } \\
\text { GGAUCAUAGGUGAUGAAGAAA }\end{array}$ \\
\hline & & Target 2 & $271-293^{\text {ii }}$ & GTGCTGTAAGCACTTATTTCAAT & $\begin{array}{l}\text { UGAAAUAAGUGCUUACAGCAC } \\
\text { GCUGUAAGCACUUAUUUCAAU }\end{array}$ \\
\hline \multirow{2}{*}{4} & \multirow{2}{*}{ gi|592746861 } & Target 1 & $186-208^{\mathrm{ii}}$ & TAGGATCATAGGTGATGAAGAAA & $\begin{array}{l}\text { UCUUCAUCACCUAUGAUCCUA } \\
\text { GGAUCAUAGGUGAUGAAGAAA }\end{array}$ \\
\hline & & Target 2 & $271-293^{\text {ii }}$ & GTGCTGTAAGCACCAATTTCAAT & $\begin{array}{l}\text { UGAAAUUGGUGCUUACAGCAC } \\
\text { GCUGUAAGCACCAAUUUCAAU }\end{array}$ \\
\hline 5 & gi|592746862 & Target 1 & $271-293^{\mathrm{ii}}$ & GTGCTGTAAGCACCAATTTCAAT & $\begin{array}{l}\text { UGAAAUUGGUGCUUACAGCAC } \\
\text { GCUGUAAGCACCAAUUUCAAU }\end{array}$ \\
\hline \multirow{2}{*}{6} & \multirow{2}{*}{ gi|592746863 } & Target 1 & $186-208^{\mathrm{ii}}$ & TAGGATCATAGGTGATGAAGAAA & $\begin{array}{l}\text { UCUUCAUCACCUAUGAUCCUA } \\
\text { GGAUCAUAGGUGAUGAAGAAA }\end{array}$ \\
\hline & & Target 2 & $271-293$ ii & GTGCTGTAAGCACCAATTTCAAT & $\begin{array}{l}\text { UGAAAUUGGUGCUUACAGCAC } \\
\text { GCUGUAAGCACCAAUUUCAAU }\end{array}$ \\
\hline \multirow{2}{*}{7} & \multirow{2}{*}{ gi|592746864 } & Target 1 & $186-208^{\text {ii }}$ & TAGGATCATAGGTGATGAAGAAA & $\begin{array}{l}\text { UCUUCAUCACCUAUGAUCCUA } \\
\text { GGAUCAUAGGUGAUGAAGAAA }\end{array}$ \\
\hline & & Target 2 & $271-293^{\text {ii }}$ & GTGCTGTAAGCACCAATTTCAAT & $\begin{array}{l}\text { UGAAAUUGGUGCUUACAGCAC } \\
\text { GCUGUAAGCACCAAUUUCAAU }\end{array}$ \\
\hline 8 & gi|592746865 & Target 1 & $186-208^{\mathrm{i}}$ & CAGGATCATAGGTGATGAAGAAA & $\begin{array}{l}\text { UCUUCAUCACCUAUGAUCCUG } \\
\text { GGAUCAUAGGUGAUGAAGAAA }\end{array}$ \\
\hline 9 & gi|592746866 & Target 1 & $186-208^{\mathrm{i}}$ & CAGGATCATAGGTGATGAAGAAA & $\begin{array}{l}\text { UCUUCAUCACCUAUGAUCCUG } \\
\text { GGAUCAUAGGUGAUGAAGAAA }\end{array}$ \\
\hline 10 & gi|592746867 & Target 1 & $186-208^{\mathrm{i}}$ & ACGGATCATAGGTGATGAAGAGA & $\begin{array}{l}\text { UCUUCAUCACCUAUGAUCCGU } \\
\text { GGAUCAUAGGUGAUGAAGAGA }\end{array}$ \\
\hline
\end{tabular}




\section{Supplementary Table: Cont'd}

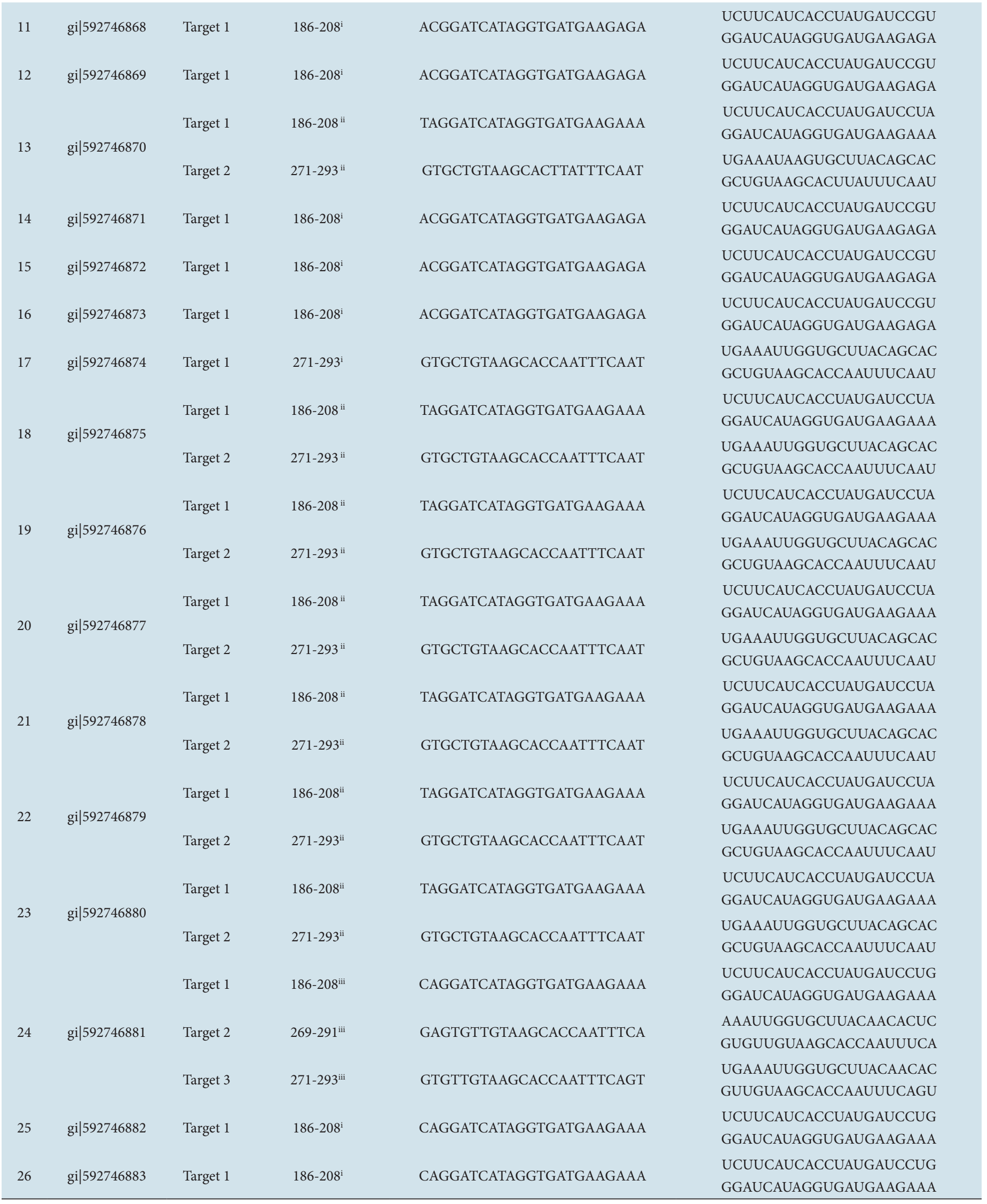




\begin{tabular}{|c|c|c|c|c|c|}
\hline \multirow{2}{*}{27} & \multirow{2}{*}{ gi|592746884 } & \multirow{2}{*}{ Target 1} & \multirow{2}{*}{$186-208^{\mathrm{i}}$} & \multirow{2}{*}{ CAGGATCATAGGTGATGAAGAAA } & UCUUCAUCACCUAUGAUCCUG \\
\hline & & & & & GGAUCAUAGGUGAUGAAGAAA \\
\hline 28 & gi|592746885 & Target 1 & $186-208^{\mathrm{i}}$ & CAGGATCATAGGTGATGAAGAAA & $\begin{array}{l}\text { UCUUCAUCACCUAUGAUCCUG } \\
\text { GGAUCAUAGGUGAUGAAGAAA }\end{array}$ \\
\hline \multirow{2}{*}{29} & \multirow{2}{*}{ gi|592746886 } & Target 1 & $186-208^{\mathrm{ii}}$ & TAGGATCATAGGTGATGAAGAAA & $\begin{array}{l}\text { UCUUCAUCACCUAUGAUCCUA } \\
\text { GGAUCAUAGGUGAUGAAGAAA }\end{array}$ \\
\hline & & Target 2 & $271-293^{\mathrm{ii}}$ & GTGCTGTAAGCACCAATTCTAGT & $\begin{array}{l}\text { UAGAAUUGGUGCUUACAGCAC } \\
\text { GCUGUAAGCACCAAUUCUAGU }\end{array}$ \\
\hline \multirow{2}{*}{30} & \multirow{2}{*}{ gi|592746887 } & Target 1 & $186-208^{\mathrm{ii}}$ & TAGGATCATAGGTGATGAAGAAA & $\begin{array}{l}\text { UCUUCAUCACCUAUGAUCCUA } \\
\text { GGAUCAUAGGUGAUGAAGAAA }\end{array}$ \\
\hline & & Target 2 & $271-293^{i i}$ & GTGCTGTAAGCACCAATTCTAGT & $\begin{array}{l}\text { UAGAAUUGGUGCUUACAGCAC } \\
\text { GCUGUAAGCACCAAUUCUAGU }\end{array}$ \\
\hline \multirow{2}{*}{31} & \multirow{2}{*}{ gi|592746888 } & Target 1 & $186-208^{\mathrm{ii}}$ & TAGGATCATAGGTGATGAAGAAA & $\begin{array}{l}\text { UCUUCAUCACCUAUGAUCCUA } \\
\text { GGAUCAUAGGUGAUGAAGAAA }\end{array}$ \\
\hline & & Target 2 & $271-293^{\mathrm{ii}}$ & GTGCTGTAAGCACCAATTCTAGT & $\begin{array}{l}\text { UAGAAUUGGUGCUUACAGCAC } \\
\text { GCUGUAAGCACCAAUUCUAGU }\end{array}$ \\
\hline \multirow{2}{*}{32} & \multirow{2}{*}{ gi|592746889 } & Target 1 & $186-208^{\mathrm{ii}}$ & TAGGATCATAGGTGATGAAGAAA & $\begin{array}{l}\text { UCUUCAUCACCUAUGAUCCUA } \\
\text { GGAUCAUAGGUGAUGAAGAAA }\end{array}$ \\
\hline & & Target 2 & $271-293^{\mathrm{ii}}$ & GTGCTGTAAGCACCAATTTCAAT & $\begin{array}{l}\text { UGAAAUUGGUGCUUACAGCAC } \\
\text { GCUGUAAGCACCAAUUUCAAU }\end{array}$ \\
\hline 33 & gil592746890 & Target 1 & $186-208^{\mathrm{ii}}$ & TAGGATCATAGGTGATGAAGAAA & $\begin{array}{l}\text { UCUUCAUCACCUAUGAUCCUA } \\
\text { GGAUCAUAGGUGAUGAAGAAA }\end{array}$ \\
\hline & & Target 2 & $271-293^{\mathrm{ii}}$ & GTGCTGTAAGCACCAATTCTAGT & $\begin{array}{l}\text { UAGAAUUGGUGCUUACAGCAC } \\
\text { GCUGUAAGCACCAAUUCUAGU }\end{array}$ \\
\hline 24 & 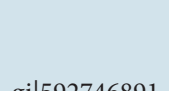 & Target 1 & $186-208^{\mathrm{ii}}$ & TAGGATCATAGGTGATGAAGAAA & $\begin{array}{l}\text { UCUUCAUCACCUAUGAUCCUA } \\
\text { GGAUCAUAGGUGAUGAAGAAA }\end{array}$ \\
\hline 34 & (1) & Target 2 & $271-293^{\mathrm{ii}}$ & GTGCTGTAAGCACCAATTCTAGT & $\begin{array}{l}\text { UAGAAUUGGUGCUUACAGCAC } \\
\text { GCUGUAAGCACCAAUUCUAGU }\end{array}$ \\
\hline 35 & gil592746892 & Target 1 & $186-208^{\mathrm{ii}}$ & TAGGATCATAGGTGATGAAGAAA & $\begin{array}{l}\text { UCUUCAUCACCUAUGAUCCUA } \\
\text { GGAUCAUAGGUGAUGAAGAAA }\end{array}$ \\
\hline & 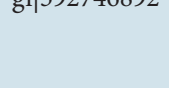 & Target 2 & $271-293^{\mathrm{ii}}$ & GTGCTGTAAGCACCAATTCTAGT & $\begin{array}{l}\text { UAGAAUUGGUGCUUACAGCAC } \\
\text { GCUGUAAGCACCAAUUCUAGU }\end{array}$ \\
\hline 36 & gi|592746893 & Target 1 & $186-208^{\mathrm{i}}$ & ACGGATCATAGGTGATGAAGAGA & $\begin{array}{l}\text { UCUUCAUCACCUAUGAUCCGU } \\
\text { GGAUCAUAGGUGAUGAAGAGA }\end{array}$ \\
\hline 27 & Fil502746894 & Target 1 & $186-208^{\mathrm{ii}}$ & TAGGATCATAGGTGATGAAGAAA & $\begin{array}{l}\text { UCUUCAUCACCUAUGAUCCUA } \\
\text { GGAUCAUAGGUGAUGAAGAAA }\end{array}$ \\
\hline (1) & 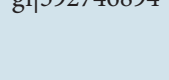 & Target 2 & $271-293^{\mathrm{ii}}$ & GTGCTGTAAGCACCAATTTCAAT & $\begin{array}{l}\text { UGAAAUUGGUGCUUACAGCAC } \\
\text { GCUGUAAGCACCAAUUUCAAU }\end{array}$ \\
\hline
\end{tabular}

Here, Predicted maximum 3 siRNA target positions of 37different strains of Zika virus used in this study: 1 target position, 2 target positions and 3 target positions were represented by 3 characters: i, ii, and iii respectively.

In this computational approach all the parameters and tools used for the designing potential antiviral RNA against the 37 different Strains of Zika virus supports the efficiency of antiviral RNA against their target sequences. This study successfully designed four consensus siRNA against four consensus target group which fulfill all the criteria of a siRNA molecule as therapeutic agent. So, these potential siRNA molecules might be used as potential RNA based therapeutics in advanced RNAi technology for the treatment of Zika virus infection.

\section{CONCLUSION}

This work supports the hypothesis that rate of viral replication and degree of pathogenicity in Zika virus infection can be reduced by predicted siRNA in this study. Apart from this, present investigation will help scientists toward understanding the prediction of antiviral RNA based therapeutics. However, experimental approaches and validation will be required for establishing this hypothesis.

\section{ACKNOWLEDGEMENT}

We acknowledge the Department of Biochemistry and Biotechnology, USTC for logistic supports to accomplish the work.

\section{CONFLICTS OF INTEREST}

The authors declare that there is no conflict of interests. 


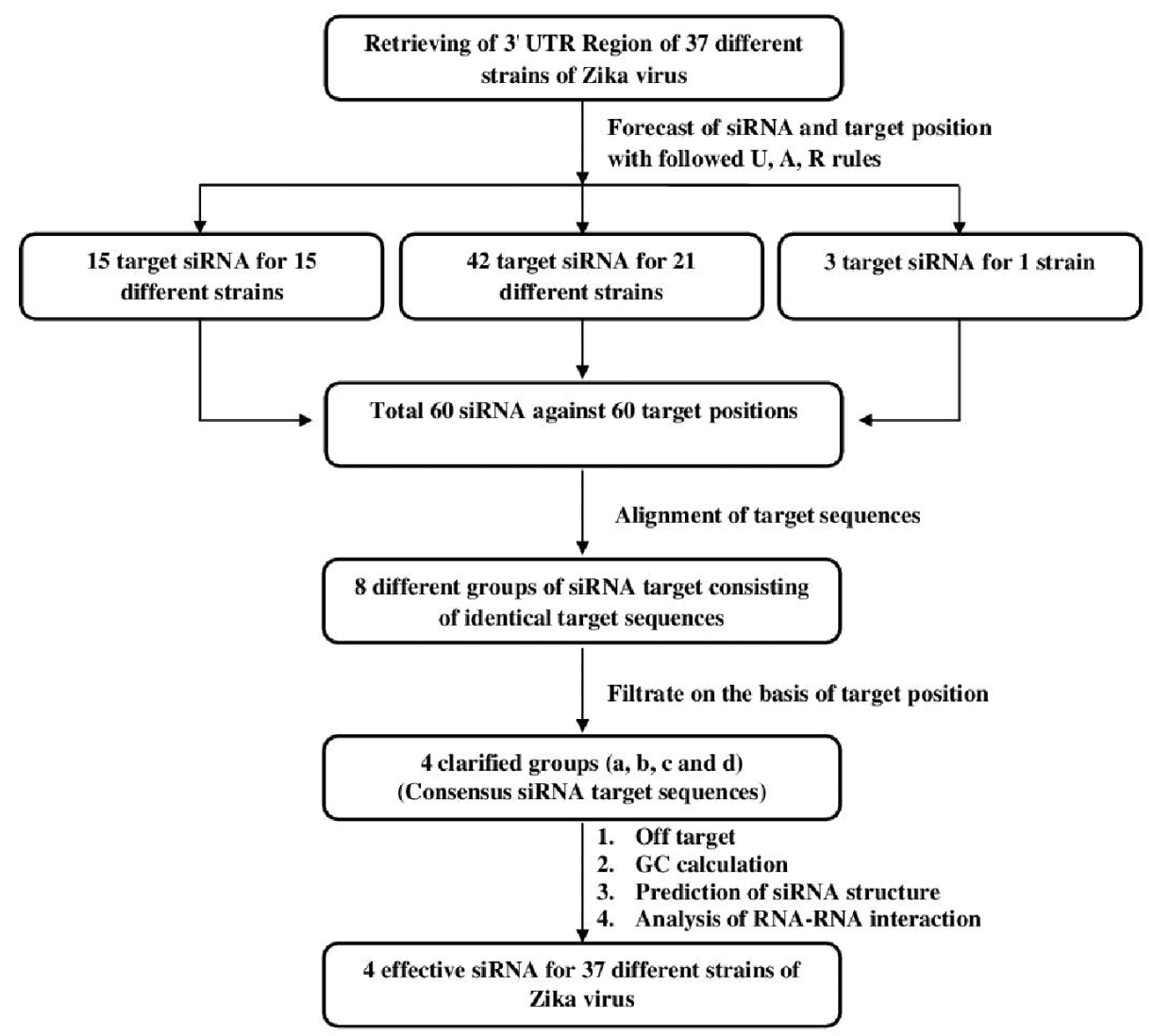

Figure 1:Flowchartshowingthecompleteapproachesusedforscreening ofeffectivesiRNAmoleculesagainst3'UTRregionof37differentstrainsofZikavirusinthisstudy.

\begin{tabular}{|c|c|c|c|}
\hline \multicolumn{2}{|c|}{ Consensus target group - a } & \multicolumn{2}{|c|}{ Consensus target group - b } \\
\hline gil592746858 Target2 & GTGCTGTAAGCACCAATTTCAAT & gil592746858 Targetl & TAGGATCATAGGTGATGAAGAAA \\
\hline gil592746859 Target2 & GTGCTGTAAGCACCAATTTCAAT & gil592746859 Targetl & TAGGATCATAGGTGATGAAGAAA \\
\hline gil592746861 Target2 & GTGCTGTAAGCACCAATTTCAAT & gi|592746860 Targetl & TAGGATCATAGGTGATGAAGAAA \\
\hline gil592746862 Targetl & GTGCTGTAAGCACCAATTTCAAT & gil592746861 Targetl & TAGGATCATAGGTGATGAAGAAA \\
\hline gil592746863 Target2 & GTGCTGTAAGCACCAATTTCAAT & gil592746863 Targetl & TAGGATCATAGGTGATGAAGAAA \\
\hline gil592746864 Target2 & GTGCTGTAAGCACCAATTTCAAT & gi|592746864 Targetl & TAGGATCATAGGTGATGAAGAAA \\
\hline gil592746874 Target1 & GTGCTGTAAGCACCAATTTCAAT & gil592746870 Targetl & TAGGATCATAGGTGATGAAGAAA \\
\hline gil592746875 Target2 & GTGCTGTAAGCACCAATTTCAAT & gil592746875 Targetl & TAGGATCATAGGTGATGAAGAAA \\
\hline gil592746876 Target2 & GTGCTGTAAGCACCAATTTCAAT & gi|592746876 Target1 & TAGGATCATAGGTGATGAAGAAA \\
\hline gil592746877 Target2 & GTGCTGTAAGCACCAATTTCAAT & gi|592746877 Target1 & TAGGATCATAGGTGATGAAGAAA \\
\hline gil592746878 Target2 & GTGCTGTAAGCACCAATTTCAAT & gil592746878 Targetl & TAGGATCATAGGTGATGAAGAAA \\
\hline gil592746879 Target2 & GTGCTGTAAGCACCAATTTCAAT & gi|592746879 Targetl & TAGGATCATAGGTGATGAAGAAA \\
\hline gil592746880 Target2 & GTGCTGTAAGCACCAATTTCAAT & gil592746880 Targetl & TAGGATCATAGGTGATGAAGAAA \\
\hline gil592746889 Target2 & GTGCTGTAAGCACCAATTTCAAT & gi|592746886 Targetl & TAGGATCATAGGTGATGAAGAAA \\
\hline \multirow[t]{7}{*}{ gil592746894 Target2 } & GTGCTGTAAGCACCAATTTCAAT & gil592746887 Targetl & TAGGATCATAGGTGATGAAGAAA \\
\hline & & gi|592746888 Targetl & TAGGATCATAGGTGATGAAGAAA \\
\hline & & gil592746889 Targetl & TAGGATCATAGGTGATGAAGAAA \\
\hline & & gil592746890 Targetl & TAGGATCATAGGTGATGAAGAAA \\
\hline & & gil592746891 Targetl & TAGGATCATAGGTGATGAAGAAA \\
\hline & & gil592746892 Targetl & TAGGATCATAGGTGATGAAGAAA \\
\hline & & gi|592746894 Targetl & TAGGATCATAGGTGATGAAGAAA \\
\hline \multicolumn{2}{|c|}{ Consensus target group - c } & \multicolumn{2}{|c|}{ Consensus target group - $d$} \\
\hline gil592746865 Target1 & CAGGATCATAGGTGATGAAGAAA & gil592746867 Targetl & ACGGATCATAGGTGATGAAGAGA \\
\hline gil592746866 Target1 & CAGGATCATAGGTGATGAAGAAA & gil592746868 Targetl & ACGGATCATAGGTGATGAAGAGA \\
\hline gil592746881 Target1 & CAGGATCATAGGTGATGAAGAAA & gil592746869 Targetl & ACGGATCATAGGTGATGAAGAGA \\
\hline gil592746882 Target1 & CAGGATCATAGGTGATGAAGAAA & gil592746871 Targetl & ACGGATCATAGGTGATGAAGAGA \\
\hline gil592746883 Target1 & CAGGATCATAGGTGATGAAGAAA & gil592746872 Targetl & ACGGATCATAGGTGATGAAGAGA \\
\hline gil592746884 Targetl & CAGGATCATAGGTGATGAAGAAA & gi|592746873 Targetl & ACGGATCATAGGTGATGAAGAGA \\
\hline gil592746885 Target1 & CAGGATCATAGGTGATGAAGAAA & gil592746893 Targetl & ACGGATCATAGGTGATGAAGAGA \\
\hline
\end{tabular}

Figure 2: Predicted 4 different consensus siRNA target sequences ( $a, b, c$ and d) by Clustal W 


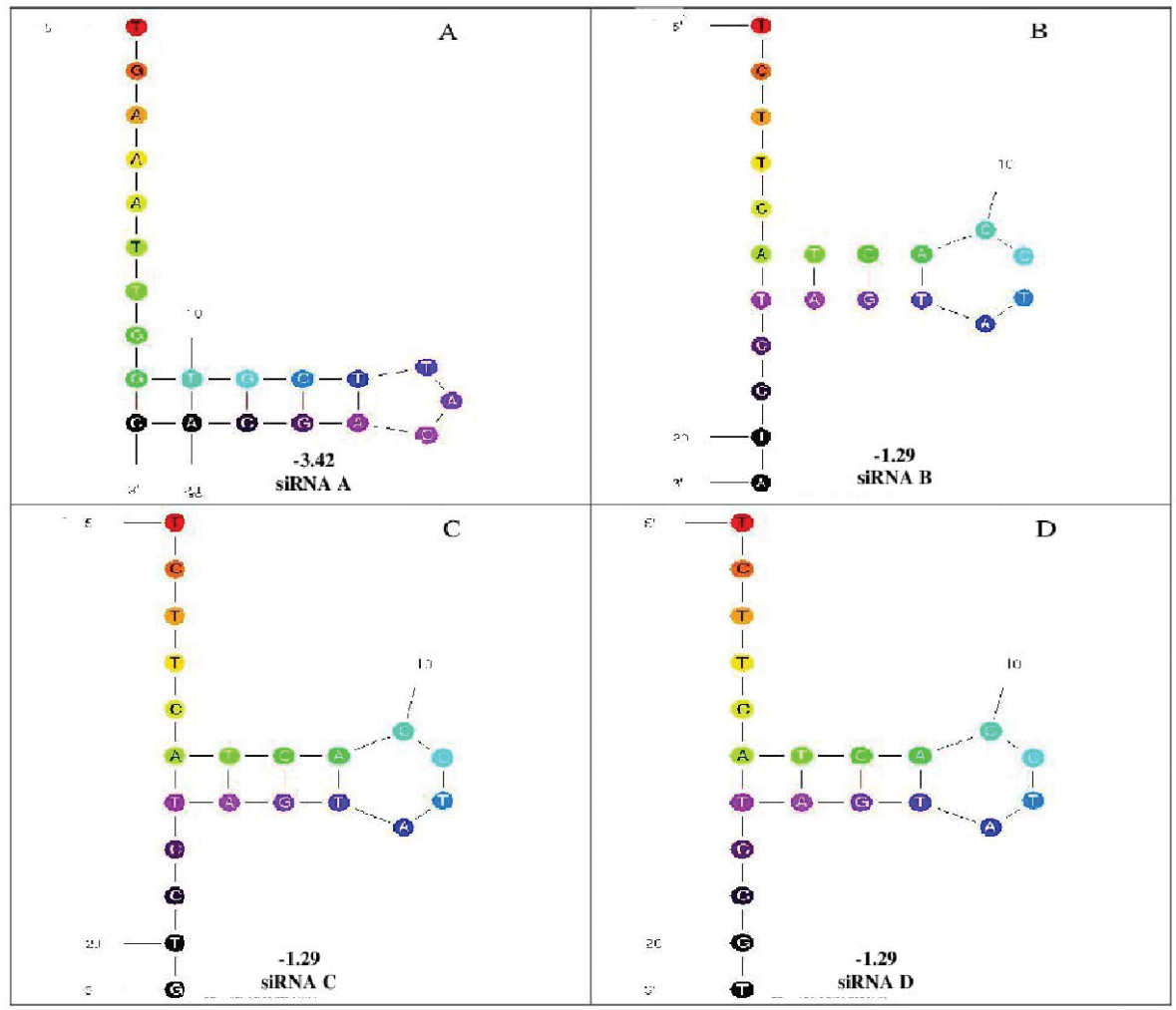

Figure 3: Predicted 4 siRNA (A, B, C and D) secondary structures with possible folding and minimum free energy.

\section{ABBREVIATION USED}

M.A: Mohammad Abul; Md: Mohammad; USTC: University of Science and Technology Chittagong.

\section{REFERENCES}

1. Dick GW, Kitchen SF, Haddow AJ. Zika virus. I. Isolations and serological specificity. Trans R Soc Trop Med Hyg. 1952;46(5):509-20.

2. Darwish MA, Hoogstraal H, Roberts TJ, Ahmed IP, Omar F. A sero-epidemiological survey for certain arboviruses (Togaviridae) in Pakistan. Trans R Soc Trop Med Hyg. 1983;77(4):442-5.

3. Marchette NJ, Garcia R, Rudnick A. Isolation of Zika Virus from Aedes aegypti mosquitoes in Malaysia. Am J Trop Med Hyg. 1969;18(3):411-5.

4. Olson JG, Ksiazek TG, Suhandiman, Triwibowo. Zika virus, a cause of fever in Central Java, Indonesia. Trans R Soc Trop Med Hyg. 1981;75(3):389-93.

5. Duffy MR, Chen TH, Hancock WT, Powers AM, Kool JL, Lanciotti RS, et al. Zika virus outbreak on Yap Island, Federated States of Micronesia. N Engl J Med. 2009;360(24):2536-43

6. Lanciotti RS, Kosoy OL, Laven JJ, Velez JO, Lambert AJ, Johnson AJ, et al. Genetic and serologic properties of Zika virus associated with an epidemic, Yep State, Micronesia, 2007. Emerg Infect Dis. 2008;14(8):1232-9.

7. Heang V, Yasuda $C Y$, Sovann L, Haddow AD, Travassos da Rosa AP, Tesh RB, et al. Zika virus infection, Cambodia, 2010. Emerg Infect Dis. 2012;18(2):349-51.

8. Zika reaches Bangladesh. The Times of India [cited 2016 Mar 22]. Available from: http://timesofindia.indiatimes.com/life-style/health-fitness/health-news/ Zika-reaches-Bangladesh/articleshow/51511450.cms?.

9. Hayes EB. Zika virus outside Africa. Emerg Infect Dis. 2009;15(9):1347-50.

10. Foy BD, Kobylinski KC, Chilson Foy JL, Blitvich BJ, Travassos da Rosa A, Haddow AD, et al. Probable non-vector-borne transmission of Zika virus, Colorado, USA. Emerg Infect Dis. 2011;17(5):880-2.

11. Faye $O$, Freire CCM, lamarino A, Faye O, de Oliveira JVC, Diallo $M$, et al. Molecular Evolution of Zika Virus during Its Emergence in the $20^{\text {th }}$ Century. PLoS Negl Trop Dis. 2014;8(1):e2636.

12. Rasmussen SA, Jamieson DJ, Honein MA, Petersen LR. Zika Virus and Birth Defects-Reviewing the Evidence for Causality. N Engl J Med. 2016;374(20):1981-7.

13. CDC Concludes Zika Causes Microcephaly and Other Birth Defects. Centers for Disease Control and Prevention. [updated 2016 Apr 13; cited 2016 Apr 13]. Avail- able from: http://www.cdc.gov/media/releases/2016/s0413-zika-microcephaly html.

14. Zika Virus, Microcephaly and Guillain-Barré Syndrome. World Health Organization [cited 2016 Apr 7]. Available from: http://www.who.int/emergencies/zika-virus/ situation-report/7-april-2016/en/.

15. Bangladesh still free from Zika virus. The daily observer [updated 2016 Jan 31; cited 2016 May 4]. Available from: http://www.observerbd.com/2016/01/31/ 133894.php.

16. Chambers TJ, Hahn CS, Galler R, Rice CM. Flavivirus genome organization, expression, and replication. Annu Rev Microbiol. 1990;44:649-88.

17. Gebhard LG, Filomatori CV, Gamarnik AV. Functional RNA elements in the dengue virus genome. Viruses, 2011;3(9):1739-56.

18. Chiu WW, Kinney RM, Dreher TW. Control of Translation by the 5'- and 3'-terminal regions of the dengue virus genome. J Virol. 2005;79(13):8303-15.

19. Kuno G, Chang GJ. Full-length sequencing and genomic characterization of Bagaza, Kedougou, and Zika viruses. Arch Virol, 2007;152(4):687-96.

20. Filomatori CV, Lodeiro MF, Alvarez De, Samsa MM, Pietrasanta L, Gamarnik AV. A 5' RNA element promotes dengue virus RNA synthesis on a circular genome. Genes Dev. 2006;20(16):2238-49.

21. Alvarez DE, Lodeiro MF, Ludueña SJ, Pietrasanta LI, Gamarnik AV. Longrange RNA-RNA interactions circularize the dengue virus genome. J virol. 2005;79(11):6631-43.

22. Pijlmam GP, Funk A, Kondratieva N, Leung J, Torres S, van der Aa L, Liu WJ et al. A highly structured, nuclease-resistant, noncoding RNA produced by flaviviruses is required for pathogenicity. Cell Host Microbe. 2008;4(6):579-91.

23. Zeng $L$, Falgout $B$, Markoff $L$. Identification of specific nucleotide Sequences within the conserved $3^{\prime}$-SL in the dengue type-2 virus genome required for replication. J Virol. 1998;72(9):7510-22.

24. The Nobel Prize in Physiology or Medicine 2006. Nobelprize.org [cited 2016 Apr 4]. Available from: http://www.nobelprize.org/nobel_prizes/medicine/laureates/2006/.

25. Burger K, Gullerova M. Swiss army knives: non-canonical functions of nuclea Drosha and Dicer. Nat Rev Mol Cell Biol. 2015;16(7):417-30.

26. Saengkrit N, Sanitrum P, Woramongkolchai N, Saesoo S, Pimpha N, ChalenwlertUmpon S, et al. The PEl-introduced C S shell/PMMA core nanoparticle for silencing the expression of E6/E7 oncogenes in human cervical cells. Carbohydr Polym. 2012;90(3):1323-9

27. Geall AJ, Verma A, Otten GR, Shaw CA, Hekela A, Banerjee K, et al. Non- 
viral delivery of self-amplifying RNA vaccines. Proc Natl Acad Sci U S A. 2012;109(36):1460-9.

28. Boudreau RL, Davidson BL. RNAi therapeutics for CNS disorders. Brain Res. 2010;1338;112-21.

29. Nur SM, Amin MA, Alam R, Hasan MA, Hossain MA, Mannan A. An in silico approach to design potential siRNA molecules for ICP22 (US1) gene silencing of different strains of human herpes simplex 1. J Young Pharm. 2013;5(2):46-49.

30. Czech MP, Aouadi M, Tesz GJ. RNAi-based therapeutic strategies for metabolic disease. Nat Rev Endocrinol. 2011;7:473-84.

31. Chen $Y$, Cheng G, Mahato RI. RNAi for treating hepatitis B viral infection. Pharm Res. 2008;25(1):72-86.

32. Motavaf M, Safari S, Alavian SM. Therapeutic potential of RNA interference: a new molecular approach to antiviral treatment for hepatitis C. J Viral Hepat. 2012;19:757-65.

33. National Center of Biotechnology Information (NCBI) [cited 2016 May 4]. Available from: http://www.ncbi.nlm.nih.gov.

34. Naito Y, Yoshimura J, Morishita S, Ui-Tei K. siDirect 2.0: update software for designing functional siRNA with reduced seed-dependent off-target effect. BMC Bioinformatics. 2009;10:392. [cited 2016 May 4]. Available from: http:// sidirect2.rnai.jp/design.cgi.

35. Ui-Tei K, Naito Y, Takahashi F, Haraguchi T, OhkiHamazaki H, Juni A, et al. Guidelines for the selection of highly effective siRNA sequences for mammalian and chick RNA interference. Nucleic Acids Res. 2004;32(3):936-48.

36. Amarzguioui $M$, Prydz $H$. An algorithm for selection of functional siRNA sequences. Biochem Biophys Res Commun. 2004;316(4):1050-8.
37. Reynolds A, Leake D, Boese Q, Scaringe S, Marshall WS, Khvorova A. Rational siRNA design for RNA interference. Nat Biotechnol. 2004;22(3):326-30.

38. Thompson JD, Higgins DG, Gibson TJ. CLUSTAL W: improving the sensitivity of progressive multiple sequence alignment through sequence weighting position-specific gap penalties and weight matrix choice. Nucleic Acid Res. 1994;22(22):4673-80. [cited 2016 May 4]. Available from: http://www.genome. jp/tools/ClustalW.

39. Altschul SF., Gish W., Miller W., Myers EW., Lipman DJ. Basic local alignment search tool. J Mol Biol. 1990;215(3):403-10. [cited 2016 May 4]. Available from: http://genome.ucsc.edu/cgi-bin/hgBlat.

40. ENDMEMO. DNA/RNA GC content calculator [cited 2016 May 4]. Available from: http://www.endmemo.com/bio/gc.php.

41. The RNA Institute. The mfold Web Server [cited 2016 May 4]. Available from: http://unafold.rna.albany.edu/?q=mfold.

42. RNAcofold WebServer [cited 2016 May 4]. Available from: http://rna.tbi.univie. ac.at/cgi-bin/RNAcofold.cgi.

43. Ui-Tei K, Naito Y, Nishi K, Juni A, Saigo K. Thermodynamic stability and WatsonCrick base pairing in the seed duplex are major determinants of the efficiency of the siRNA-based off-target effect. Nucleic Acids Res. 2008;36(22):7100-9.

44. Chan CY, Carmack CS, Long DD, Maliyekkel A, Shao Y, Roninson IB, et al. A structural interpretation of effect of GC-content on efficiency of RNA interference. BMC Bioinformatics. 2009;10Suppl 1:S33.

45. Singh S, Gupta SK, Nischal A, Khattri S, Pant KK, Seth PK. Design of potential siRNA molecules for hepatitis delta virus gene silencing. Bioinformation. 2012;8(16):749-57.

Article History: Submission Date: 15-06-16; Revision Date: 04-07-16; Accepted Date: 07-08-16.

Cite this article: Hashem MA, Shuvo MA, Arifuzzaman. A Computational Approach to Design Potential Antiviral RNA for 3'UTR Post Transcriptional Gene Silencing of Different Strains of Zika Virus. J Young Pharm. 2017;9(1):23-30. 